\title{
A produção de cacau como meio de geração de renda e de recuperação ambiental da
}

\section{mata atlântica}

\author{
Cocoa production as a means of income generation and environmental recovery of the atlantic \\ forest
}

La producción de cacao como medio para la generación de ingresos y la recuperación ambiental del bosque atlántico

João Carlos de Pádua Andrade ORCID: https://orcid.org/0000-0002-0284-5651 Universidade Estadual de Santa Cruz, Brasil E-mail: jcpandrade@uesc.br

Paulo Sérgio Vila Nova Souza ORCID: https://orcid.org/0000-0001-6651-6198 Econamfi Projetos e Pesquisa, Brasil E-mail: paulosvns@gmail.com

Katianny Gomes Santana Estival ORCID: https://orcid.org/0000-0002-3495-6356 Universidade Estadual de Santa Cruz, Brasil E-mail: ksgestival@uesc.br

Alessandro Coelho Marques
ORCID: https://orcid.org/0000-0002-3509-3724
Instituto Ciclos de Sociedade e Cidadania, Brasil
E-mail: alessandro.marques@ciclos.org.br
Alexandre Schiavetti
ORCID: https://orcid.org/0000-0001-8429-7646
Universidade Estadual de Santa Cruz, Brasil
E-mail: aleschi@uesc.br
Zina Angelica Caceres Benavides
ORCID: https://orcid.org/0000-0003-4969-1829
Universidade Estadual de Santa Cruz, Brasil
E-mail: zacbenavides@uesc.br
Juliana Martins Vogel
ORCID: https://orcid.org/0000-0002-2701-8927
Universidade Estadual de Santa Cruz, Brasil
E-mail: juliana.vogel@gmail.com

\section{Resumo}

O sul da Bahia apresenta importantes remanescentes do bioma da Mata Atlântica. Existem duas formas de preservá-las, através das unidades de conservação e também pelo sistema de produção de cacau (Theobroma cacao). Este último funciona sob as árvores nativas do bioma e enfrentou uma grave crise, que começou em meados da década de 1980 pela tendência negativa dos preços de cacau bulk no mercado internacional e foi agravada pela praga vassoura-de-bruxa (Moniliophtora perniciosa), de consideráveis impactos negativos seja na produtividade da lavoura de cacau e/ou pelo uso dos recursos naturais. Foram realizadas pesquisas no intuito de identificar soluções, como é o caso da introdução de clones de cacau mais tolerantes à Moniliophtora perniciosa. Entretanto, a introdução do Sistema AgroFlorestal (SAF) no MAPES (Mosaico de Áreas Protegidas do Extremo Sul da Bahia) apresentou o potencial de incentivar nos agricultores a produção de cacau, pois segundo a modelagem econômica, proposta por este artigo, foi demonstrada viabilidade econômica na projeção temporal de vinte anos. Além dos retornos financeiros, que superaram as taxas de custos do Sistema Agroflorestal composto pelo cacau (espécie exótica) e outros 52 indivíduos de espécies nativas, temse a possibilidade de incrementar a vegetação nativa do bioma da Mata Atlântica.

Palavras-chave: Sistema cabruca; Sistema agroflorestal; Viabilidade econômica; MAPES.

\section{Abstract}

The south of Bahia has important remnants of the Atlantic Forest biome. There are two ways to preserve such remnants through conservation units and also through the cocoa production system (Theobroma cacao). The latter works under the native trees of the biome and faced a serious crisis, which began in the mid-1980s due to the negative trend of bulk cocoa prices in the international market and aggravated by the witches' broom pest (Moniliophtora perniciosa), of considerable negative impacts either on the productivity of the cocoa crop and / or by the use of natural resources. 
Research was carried out in order to identify solutions in case of the introduction of cocoa clones more tolerant to the harmful Moniliophtora. However, the introduction of the AgroFlorestal System (SAF) in MAPES presented the potential to encourage cocoa production in farmers, because according to the economic modeling proposed by this article, it demonstrated an economic viability in the twenty-year time projection. In addition to the financial returns, which exceeded the cost rates of the Agroforestry System composed of cocoa (exotic species) and 52 other individuals of native species, there is the possibility of increasing the native vegetation of the Atlantic Forest biome.

Keywords: Cabruca system; Agroforestry system; Economic viability; MAPES.

\section{Resumen}

El sur de Bahía tiene importantes remanentes del bioma de la Mata Atlántica. Hay dos formas de preservarlos, a través de las Unidades de Conservación y también por medio del Sistema de producción de cacao (Theobroma cacao). Este último trabaja bajo la sombra de los árboles nativos del bioma e históricamente enfrentó una grave crisis, iniciada a mediados de la década de 1980, provocada por la tendencia negativa de los precios del cacao commoditie en el mercado internacional y después por la plaga de la escoba de la bruja (Moniliophtora perniciosa). Eso en consecuencia impactó negativamente la productividad del cultivo del cacao y el uso de los recursos naturales. Se realizaron investigaciones para identificar alternativas, como la introducción de clones de cacao más tolerantes a la dañina Moniliophtora. Sin embargo, la introducción del Sistema AgroFlorestal (SAF) en MAPES (Mosaico de Áreas Protegidas en el Extremo Sur de Bahía) mostró mayor potencial para incentivar la producción de cacao en los agricultores. De acuerdo con el modelo económico propuesto por este artículo se demostró la viabilidad económica para una proyección temporal de veinte años. Además de los retornos económicos, que superaron las tasas del costo del Sistema Agroforestal compuesto por cacao (especies exóticas) y otros 52 individuos de especies nativas, existe la posibilidad de incrementar la vegetación nativa del bioma de la Mata Atlántica.

Palabras clave: Sistema cabruca; Sistema agroforestal; Viabilidad económica; MAPES.

\section{Introdução}

As ações humanas, que buscam promover o desenvolvimento econômico, carregam consigo a estigma de provocar danos ao meio ambiente. O bioma Mata Atlântica vem sofrendo ações de desmatamento desde o momento que os navegadores portugueses chegaram ao continente. Por outro lado, na mesma região que esses navegadores descobriram o Brasil, extremo sul da Bahia, os remanescentes do bioma Mata Atlântica, ecossistema no qual a aplicação da legislação ambiental tem sido objeto de intensas discussões técnico-jurídicas (Dortzbach et al., 2021, p. 1), continuam sendo preservados através de unidades de conservação legalmente constituídas e por políticas públicas, as quais buscam garantir a existência desse patrimônio ecológico.

A existência de relevantes unidades de conservação e áreas protegidas na região possibilitou a criação do Mosaico de Áreas Protegidas do Extremo Sul da Bahia (MAPES), reconhecido pelo Ministério do Meio Ambiente (Brasil, 2010). Os mosaicos de unidades de conservação foram planejados com o propósito de estabelecer uma gestão integrada e fortalecer as áreas protegidas, aproximando instituições, entes federativos e, principalmente, pessoas, unindo esforços coordenados em torno das demandas de gestão e conservação

Na região do MAPES, as dinâmicas socais e produtivas convivem com conflitos socioambientais, série de embates entre grupos sociais (Little, 2006) e decorrem da busca pelo atendimento das diversas demandas da sociedade, o que gera pressão sobre o uso e preservação dos recursos naturais (Brito et al., 2011). Regionalmente, estes conflitos abrangem não somente as tensões geradas pelas disputas do uso e apropriação dos recursos, como também, as diferentes importâncias dadas ao meio ambiente pelos atores envolvidos (Lima; Shiraishi Neto, 2015), principalmente pelas comunidades indígenas presentes nessa região.

Diante do contexto do MAPES, o presente artigo, recorte de uma ação que visa a conservação ambiental coordenada pelo Ministério do Meio Ambiente com a participação de diferentes instituições, objetiva demonstrar a viabilidade de um modelo produtivo com viés conservacionista. Esse modelo parte da dinâmica produtiva local e está sustentado em análises de viabilidade econômica e do aumento da vegetação nativa na região. 


\section{Metodologia}

\section{Área de estudo}

De acordo com a sua Portaria de criação, o Mosaico de Áreas Protegidas do Extremo Sul da Bahia abrange os municípios de Porto Seguro, Prado e Santa Cruz de Cabrália (Brasil, 2010). Entretanto, para uma análise mais aprofundada da região, foram considerados mais três municípios que estão no entorno do MAPES: Eunápolis, Itabela e Itamaraju (Figura 1).

Figura 1. Localização do MAPES, Extremo Sul da Bahia, Brasil.

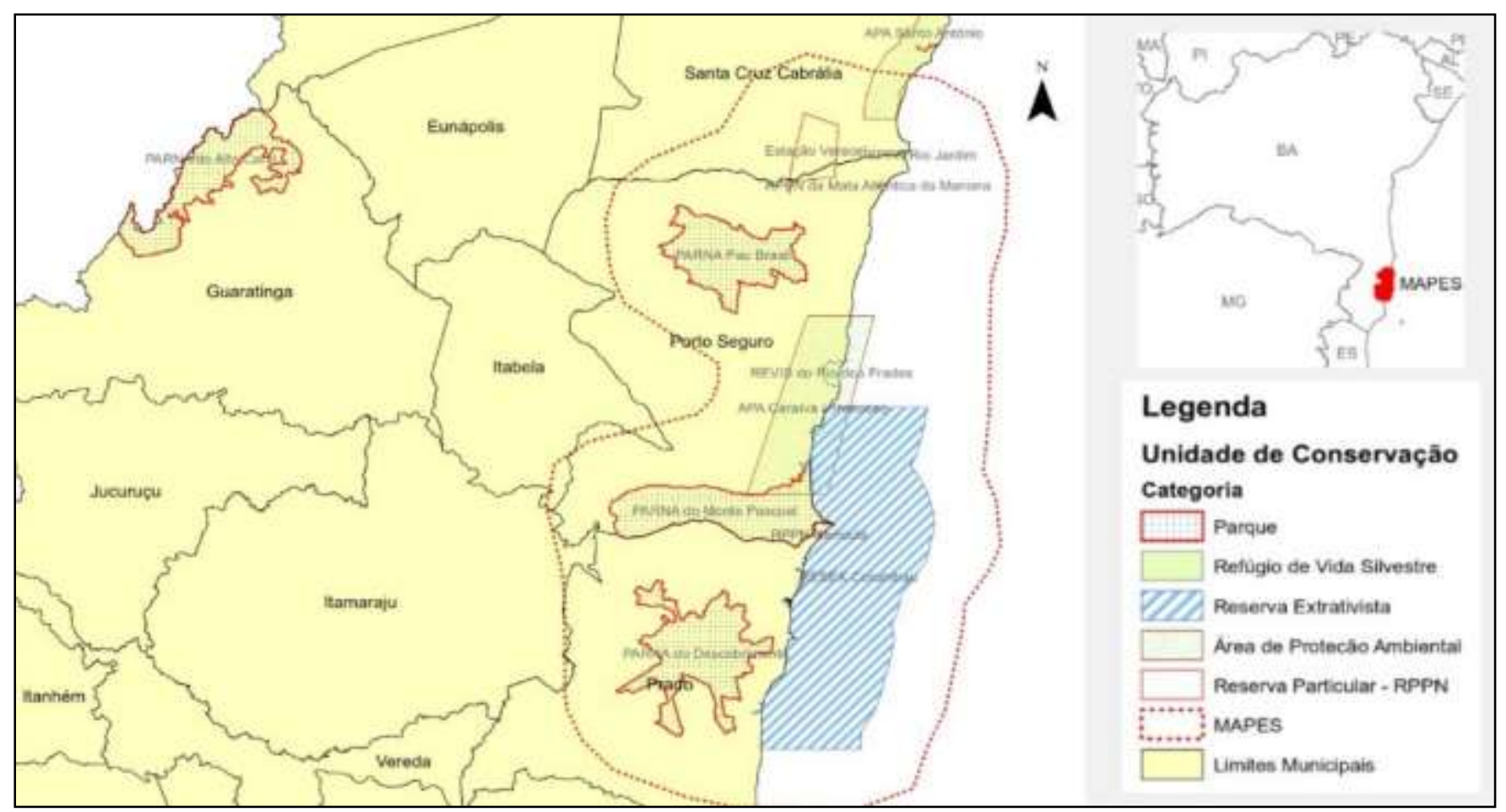

Fonte: Autores.

Os cerca de 197 mil hectares (ha) do MAPES estão distribuídos ao longo dos três municípios constantes na Portaria de criação. No seu perímetro, denota-se a presença dos Parques Nacionais (PARNA), da Reserva Extrativista (RESEX), da Área de Proteção Ambiental (APA), do Refúgio de Vida Silvestre (REVIS) e das Reservas Particulares do Patrimônio Natural (RPPN).

\section{Técnicas e definições utilizadas}

Utiliza-se o conceito de recuperação, que é a restituição de um ecossistema ou de uma população silvestre degradada a uma condição não degradada, que pode ser diferente de sua condição original (Brasil, 2000), pois corresponde ao que se almeja com o modelo produtivo proposto. Esse modelo atenderá ao exposto na Legislação Federal, especificamente, a Lei 12.651/2012 (Brasil, 2012): "Nas Áreas de Preservação Permanente, é autorizada, exclusivamente, a continuidade das atividades agrossilvipastoris, de ecoturismo e de turismo rural em áreas rurais consolidadas até 22 de julho de 2008”. A respectiva legislação estabelece: "plantio intercalado de espécies lenhosas, perenes ou de ciclo longo, exóticas com nativas de ocorrência regional, em até 50\% (cinquenta por cento) da área total a ser recomposta...", para a pequena propriedade ou posse rural familiar, incluindo os assentamentos e projetos de reforma agrária.

A partir do arcabouço legal exposto no parágrafo anterior, o modelo indicado para recuperação ambiental de Áreas de Preservação Permanente (APP) em pequena propriedade ou posse rural familiar é composto por espécies nativas e exóticas em um Sistema Agroflorestal (SAF) denominado de cabruca, cacau cultivado sob o dossel de árvores nativas da Mata Atlântica, 
responsável pela conservação dos recursos naturais (Lobão; Valeri, 2009) e formador de corredores biológicos que permitem o fluxo genético entre as populações ali presentes (Pardini, 2004). Para o SAF com base cacau e espécies nativas respeitou-se o Decreto 15.180/2014 (Bahia, 2014), que estabelece o mínimo de 40 indivíduos nativos arbóreos no sistema cabruca para que o SAF possa servir como recomposição de Reserva Legal (RL) e tenha acesso ao pagamento por serviços ambientais.

Foi utilizado um conjunto de técnicas para caracterizar a cadeia produtiva da restauração do MAPES. Esse conjunto partiu da definição de cadeia produtiva como um sistema interligado por meio de fluxos de materiais, de capital e informação (Castro; Lima; Cristo, 2002). A partir dessa definição, foram levantados dados primários não probabilísticos, obtidos através de pesquisa de campo relacionada às características produtivas do MAPES. Foram adicionados dados secundários a partir de literaturas específicas, utilizando ferramentas de geoprocessamento para mensurar o passivo ambiental existente no MAPES. Nesse caso, os dados são oriundos do Sistema Nacional de Cadastro Ambiental Rural (SICAR - até abril de 2019) a fim de verificar as áreas que necessitam de recuperação. Na Bahia, o Cadastro Ambiental Rural é realizado através da ferramenta denominada CEFIR (Cadastro Estadual Florestal de Imóveis Rurais), o qual está em sincronia com o SICAR.

Para a análise envolvendo a estrutura fundiária do MAPES, foram consideradas, as definições de propriedades de acordo com o entendimento do Instituto Nacional de Colonização e Reforma Agrária (INCRA), que estabelece também o tamanho do Módulo Fiscal (MF). Com exceção do município de Itamaraju, cujo MF corresponde a 40 ha, os demais municípios do MAPES têm MF igual a 35 ha (Brasil, 2013). A estrutura fundiária tem as seguintes definições: (i) Minifúndio - imóvel rural com dimensão inferior a 1 (MF); (ii) Pequena propriedade - imóvel rural com área compreendida entre 1 e 4 MF; (iii) Média propriedade - imóvel rural com área superior a 4 e inferior a 15 MF; (iv) Grande propriedade - o imóvel rural com área superior a $15 \mathrm{MF}$.

O modelo produtivo e de restauração indicado segue as peculiaridades locais, além de sua viabilidade econômica. Para tanto, a modelagem econômica buscou identificar os custos fixos e variáveis a partir de ações práticas na região e de pesquisas em literaturas relacionadas. Considerou-se o horizonte de 20 anos para a análise de viabilidade. Foi elaborado fluxo de caixa, tendo o Valor Presente Líquido (VPL) como principal ferramenta da análise. O processo de mensuração do VPL ocorre pela diferença positiva entre receitas e custos, atualizados de acordo com determinada Taxa Mínima de Atratividade (TMA). A análise básica consiste em: VPL negativo, o projeto não é viável economicamente a partir daquela TMA estabelecida. Quanto maior for o VPL, mais atrativo será o projeto. A TMA utilizada foi de $6 \%$ ao ano (sem considerar a inflação). Esse percentual coincide com a taxa praticada por uma relevante ação de desenvolvimento, Programa Bahia Produtiva do Governo do Estado. Adicionase também, como ferramenta de análise, a Taxa Interna de Retorno (TIR), a qual é responsável por verificar se a rentabilidade de determinado investimento é superior, inferior ou igual ao custo do capital que será utilizado para financiar o projeto. A TIR corresponde à taxa que zera o VPL. Para verificar o tempo de retorno do capital investido, utilizou-se o Payback Simples. Dessa forma, os parâmetros econômicos da atividade foram obtidos mediante análises de custo de produção e da viabilidade econômicofinanceira (Siqueira et al., 2021).

\section{Resultados e Discussão}

\section{Características socioambientais do MAPES}

A região do MAPES apresentou, num período de 34 anos, redução da vegetação natural e aumento da vegetação plantada. Em 1985, existiam 423.381 ha de vegetação natural, reduzido para 320.650 ha. Nesse mesmo período, a floresta plantada passou de 26.687 ha para 94.922 ha (Tabela 1). Em termos percentuais, a vegetação natural teve uma redução total de 24,26\% no período 1985-2019, gerando uma média anual de redução de 0,71\% nos 34 anos, enquanto a floresta plantada teve um acréscimo de 255,69\%, com média anual de 7,52\%. Esse cenário da floresta plantada deve-se ao avanço do monocultivo do eucalipto (Eucalyptus) na região. 
Tabela 1. Vegetação (em hectares) na região do MAPES: 1985-2019.

\begin{tabular}{lrr|rr}
\hline \multirow{2}{*}{ Localidades } & \multicolumn{2}{c|}{ Ano de 1985 (ha) } & \multicolumn{2}{c}{ Ano de 2019 (ha) } \\
\cline { 2 - 5 } & Natural & Plantada & \multicolumn{1}{c}{ Natural } & \multicolumn{1}{c}{ Plantada } \\
\hline Eunápolis & 27.268 & 3 & 29.087 & 14.171 \\
Itabela & 33.790 & 642 & 25.488 & 7.752 \\
Itamaraju & 82.819 & 1.171 & 61.290 & 5.377 \\
Porto Seguro & 120.222 & 7.919 & 86.866 & 25.243 \\
Prado & 71.707 & 16.849 & 48.030 & 29.209 \\
Santa Cruz de Cabrália & 87.575 & 103 & 69.889 & 13.170 \\
\hline TOTAL & $\mathbf{4 2 3 . 3 8 1}$ & $\mathbf{2 6 . 6 8 7}$ & $\mathbf{3 2 0 . 6 5 0}$ & $\mathbf{9 4 . 9 2 2}$ \\
\hline
\end{tabular}

Fonte: Elaborada a partir de dados do MapBiomas (2019).

O processo de redução da vegetação nativa no MAPES coincide com a destruição das florestas no mundo, impulsionada pela expansão desordenada das atividades agrícolas e por práticas não sustentáveis dos modos de produção (Shackelford et al., 2015; Muñoz-Sáez et al., 2017). Consequentemente, são gerados impactos negativos em toda biodiversidade associada a essas florestas, aumentando a emissão de gases do efeito estufa, reduzindo a provisão de outros serviços ecossistêmicos e diminuindo o bem-estar humano.

A degradação das florestas brasileiras e sua biodiversidade proporciona prejuízos que não vêm sendo devidamente mensurados, nem pela sociedade, nem pelos tomadores de decisão (Andrade; Fasiaben, 2009). Os diversos serviços ambientais ofertados, como regulação do fluxo dos mananciais hídricos, manutenção da fertilidade do solo, proteção das encostas, captura e estocagem de carbono pelas florestas estão sendo reduzidos à medida que essas florestas são destruídas (Constanza, 1998).

Atualmente, a região do MAPES caracteriza-se pela presença da silvicultura, produção de eucalipto e celulose visando o mercado internacional principalmente. Entre 1990 e 2013, 23 anos, o cultivo do eucalipto no MAPES apresentou um acréscimo total na área cultivada de 707\%, passando de 12.214 ha em 1990 para 98.295 ha em 2013, expansão média de 30,7\% ao ano.

A chegada do eucalipto acirrou ainda mais os conflitos socioambientais na região. Essa monocultura é acompanhada de, no mínimo, dois cenários: o primeiro é o econômico com geração de receitas para o setor público via tributos gerados e, o segundo, os impactos socioambientais que são atribuídos a essa atividade econômica. Perante esse último, denota-se que a chegada do eucalipto na região coincide com a desterritorialização de parte da sociedade rural, aumento do preço dos imóveis e perturbação no meio ecológico (Cerqueira Neto, 2012; Ferreira; Pereira; Logarezzi, 2019).

Além da silvicultura, a região do MAPES apresenta produção agrícola diversificada, com destaque para o cultivo do cacau (Theobroma cacao), do café (Coffea), da cana-de-açúcar (Saccharum officinarum), mamão (Carica papaya) e mandioca (Manihot esculenta). Ao longo de 15 anos (2001-2016), esses produtos tiveram diferentes taxas totais de crescimento: o café com 305,89\%, a cana-de-açúcar com 30,8\% e a mandioca, 39,59\%. Os cultivos de cacau e mamão apresentaram taxas de decrescimento de $14,68 \%$ e $27,99 \%$ respectivamente.

Outra atividade econômica predominante no MAPES é a pecuária extensiva, a qual tem baixa produtividade média por hectare (Barbosa et al., 2010). No sul da Bahia, existem locais com uma média de 0,81 UA/ha ${ }^{1}$ (Carvalho Júnior, 2011). Com dados do MapBiomas, foi possível identificar a existência de 437.204 ha de pastagens (ano de 2019) na área do MAPES. Essa área representa um acréscimo de 12,45\%, tendo como base o ano de 1985, cuja pastagem correspondia a 388.813 ha (Mapbiomas, 2019).

${ }^{1}$ Unidade animal por hectare. 
A partir de dados constantes no SICAR, em abril de 2019 (Brasil, 2019), foram identificados 4.215 imóveis (estabelecimentos), distribuídos em 636.097 ha, o que corresponde a 63\% da área territorial dos seis municípios do MAPES. Nos estabelecimentos predomina o minifúndio com 2.025 imóveis cadastrados, ou seja, 48\% dos imóveis (Figura 2A). Quanto à quantidade de áreas, as médias e grandes propriedades, que correspondem respectivamente a $18 \%$ e 5\% na quantidade de estabelecimentos, absorvem respectivamente 213.868 ha e 299.402 ha, ou seja, 34\% e 47\% da área total cadastrada no SICAR (Figura 2B).

Figura 2. Estrutura fundiária dos imóveis do MAPES cadastrados no SICAR até abril/2019, composta pela quantidade de estabelecimentos (A) e pela quantidade de hectares (B).

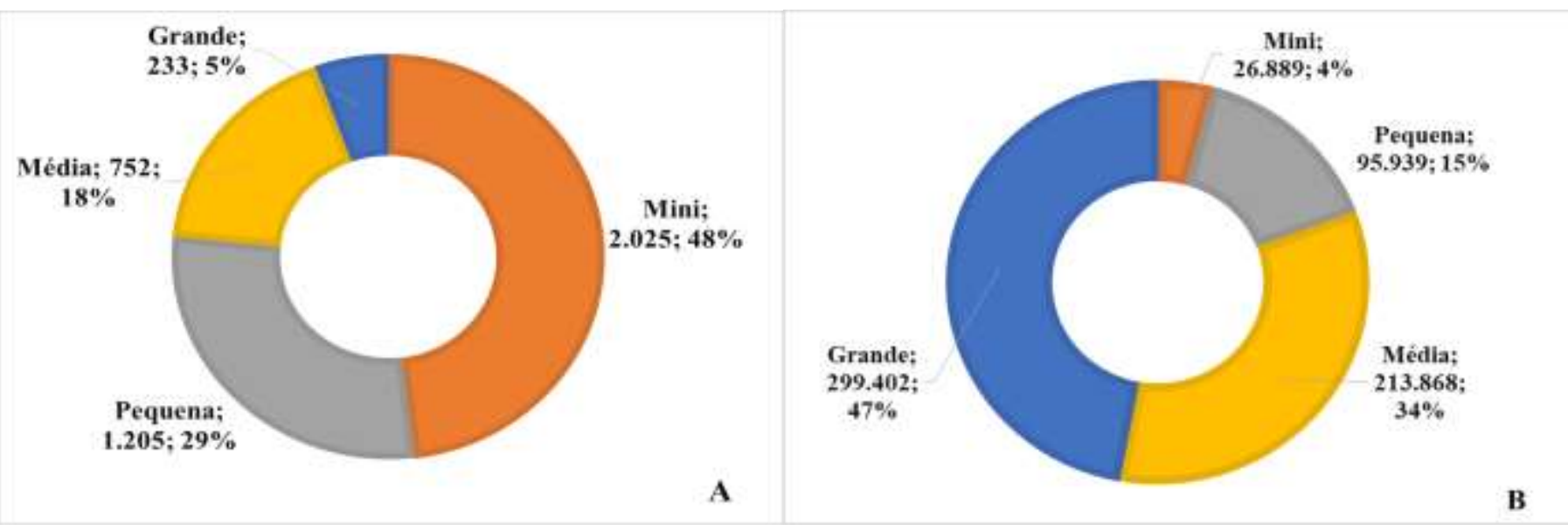

Fonte: Elaboração própria a partir Andrade et al. (2020).

O entendimento da estrutura fundiária do MAPES torna-se relevante para ações de planejamento ambiental, uma vez que as exigências legais para recomposição ambiental são diferentes para os tipos de propriedades. As ações de recuperação ou restauração também devem atentar para o Uso e Ocupação da Terra no MAPES. Relacionando a área total dos seis municípios do MAPES (1.008.133 ha) com as áreas de acordo com o volume produzido, segundo dados da Superintendência de Estudos Econômicos e Sociais da Bahia (Bahia, 2019), a pecuária cobre cerca de 50,76\%² do território dos municípios, seguida pelo eucalipto que cobre $9,75 \%$. Os demais produtos, cacau, café, cana-de-açúcar, mamão e mandioca abrangem, aproximadamente, $1 \%$.

\section{Estimativa do passivo ambiental no MAPES}

A indicação ou priorização de áreas para recuperação da vegetação na região do MAPES baseou-se nos cadastros do SICAR realizados até abril de 2019. Nos municípios de abrangência do MAPES, cerca de 63\% da extensão territorial estava cadastrada no CEFIR-SICAR em abril de 2019, excetuando Itabela com 55\% (Tabela 2). O município de Porto Seguro apresentava cadastros em 47\% da sua extensão, se adicionadas as duas unidades de conservação PARNA Pau Brasil e PARNA do Monte Pascoal, eleva-se a área para 65\% do município.

\footnotetext{
${ }^{2}$ Considerando $1 \mathrm{UA} / \mathrm{ha}$.
} 
Tabela 2. Abrangência dos registros de propriedades rurais no SICAR, 2019.

\begin{tabular}{lrrrrr}
\hline \multicolumn{1}{c}{ Municípios } & $\begin{array}{c}\text { Propriedades } \\
\text { Cadastradas } \\
\text { SICAR }\end{array}$ & $\begin{array}{c}\text { Área total } \\
\text { propriedades } \\
\text { cadastradas (ha) }\end{array}$ & $\begin{array}{c}\text { Área total do } \\
\text { município (ha) }\end{array}$ & $\begin{array}{c}\text { Área não } \\
\text { cadastrada } \\
\text { (ha) }\end{array}$ & $\begin{array}{c}\text { Extensão } \\
\text { territorial } \\
\text { cadastrada (\%) }\end{array}$ \\
\hline Eunápolis & 630 & 101.530 & 142.497 & 40.967 & 71 \\
Itabela & 383 & 50.963 & 92.426 & 41.463 & 55 \\
Itamaraju & 1.257 & 153.376 & 235.907 & 82.531 & 65 \\
Porto Seguro & 602 & 107.070 & 228.523 & 121.453 & 47 \\
Prado & 916 & 121.097 & 168.569 & 47.472 & 72 \\
S. C. Cabrália & 427 & 102.110 & 146.048 & 43.938 & 70 \\
\hline
\end{tabular}

Fonte: Andrade et al. (2020).

Ao utilizar os cadastros do CEFIR-SICAR até abril de 2019, foi estimado um passivo ambiental de 15.210 ha em APP e 22.208 ha nas RL. Consequentemente, seguindo o constante na Legislaçao específica (Brasil, 2012), o SAF Cacau poderá ser utilizado para recuperação das pequenas propriedades, ou seja, 3.165 ha (Tabela 3), desde que sejam áreas consolidadas até 22 de julho de 2008.

Tabela 3. Estimativa do passivo ambiental na região do MAPES.

\begin{tabular}{|c|c|c|c|c|}
\hline Áreas de uso restrito & Classe de Imóveis rurais & Ativo Ambiental & Passivo Ambiental & Total do Passivo \\
\hline \multirow{2}{*}{ RL } & Média propriedade & 33.746 & 10.521 & \multirow{2}{*}{22.208} \\
\hline & Grande propriedade & 42.463 & 11.687 & \\
\hline \multirow{3}{*}{ APP } & Pequena propriedade & 3.756 & 3.165 & \multirow{3}{*}{15.210} \\
\hline & Média propriedade & 8.411 & 5.657 & \\
\hline & Grande propriedade & 13.181 & 6.388 & \\
\hline TOTAL & & 101.557 & 37.418 & 37.418 \\
\hline
\end{tabular}

Fonte: Andrade et al. (2020).

\section{Análise de viabilidade do modelo de recuperação ambiental proposto para o MAPES}

Na pesquisa de campo com os agricultores e pecuaristas do MAPES, ficou evidente o diminuto interesse desses atores em processos de recuperação ambiental apenas com foco nos princípios conservacionistas. Entretanto, percebeu-se um nível de sensibilidade desses atores por modelos que possam gerar renda. Nesse sentido, e entendendo que o crédito é uma ferramenta indispensável e que as instituições financiadoras demandam por modelos produtivos que apresentem viabilidade econômica para disponibilização de créditos, o modelo indicado busca atender tanto as demandas econômicas, quanto as ambientais.

Para a pequena propriedade, respeitou-se também o limite de 50\% da área com espécies exóticas para recomposição da APP, considerando que essa área esteja consolidada com data anterior a 22 de julho de 2008 (Brasil, 2012), tendo, portanto, o somatório de 1.301 indivíduos nos primeiros anos e, com eliminação da bananeira, 884 indivíduos/ha no longo prazo, distribuídos entre exóticas (cacau) e nativas da Mata Atlântica (Tabela 4). Além disso, com 52 indivíduos de nativas, o SAF cacau poderá se beneficiar dos incentivos referentes à compensação ambiental conforme Decreto 15.180/2014 (Bahia, 2014). Como o cultivo do cacau ocorre de forma intercalada com as espécies nativas, para respeitar o limite de 50\% da área com espécie exótica, utilizouse espaçamentos de plantio que totalizam coberturas semelhantes. Assim, os 832 indivíduos de cacau com espaçamento de $4 \times 3$ metros perfazem uma área de cobertura de $9.984 \mathrm{~m}^{2}$ e as 52 nativas, ao espaçamento de $8 \times 24$ metros, atingem também $9.984 \mathrm{~m}^{2}$ de cobertura vegetal. As bananeiras são temporárias, cujo objetivo é o de sombreamento para as mudas de cacaueiro, e podem 
ser uma fonte de renda ao agricultor, podendo gerar, após 1,5 ano, uma receita total de $\mathrm{R} \$ 10.500,00 /$ ha e $\mathrm{R} \$ 8.500,00 /$ ha após 2,5 anos (Virgens Filho, 2017).

Tabela 4. Espécies e indivíduos utilizados no SAF cacau.

\begin{tabular}{lccc}
\hline & Nomes das espécies & \multicolumn{2}{c}{ Quantidades } \\
\hline \multicolumn{1}{c}{ Popular } & \multicolumn{1}{c}{ Científico } & Implantar & Manter \\
\hline Cacau & Theobroma cacao & 832 & 832 \\
Banana & Musa paradisiaca & 417 & 0 \\
Pau-brasil & Paubrasilia echinata & 1 & 1 \\
Jequitibá & Cariniana legalis & 1 & 1 \\
Pau-viola & Cytharexyllum myrianthum & 2 & 2 \\
Massaranduba & Manilkara bidentata & 1 & 1 \\
Embaúba & Cecropia pachystachya & 5 & 5 \\
Ipê-rosa & Handroanthus heptaphyllus & 2 & 2 \\
Ingá-feijão & Inga marginata & 5 & 5 \\
Jatobá & Hymenaea courbaril & 2 & 2 \\
Sapucaia & Lecythis pisonis & 33 & 33 \\
\hline TOTAL & & $\mathbf{1 . 3 0 1}$ & $\mathbf{8 8 4}$ \\
\hline
\end{tabular}

Fonte: Elaboração própria a partir de Andrade et al. (2020).

A cacauicultura, atividade secular, promoveu a geração de riqueza, prosperidade e criação de cidades (Rocha, 2008). Entretanto, as crises comerciais (queda do preço internacional do cacau em meados da década de 1980) e produtivas (aparecimento da doença vassoura-de-bruxa - Moniliophtora perniciosa - nos finais dos anos de 1980), geraram consideráveis prejuízos para a economia local e impactos negativos sobre os recursos ambientais (Andrade et al., 2015). Pesquisas foram realizadas a fim de identificar soluções, o que resultou em novos clones mais tolerantes e produtivos. Nesse sentido, o SAF cacau indicado tem sua sustentação na utilização dos melhores clones, a exemplo do PS1319 e do CCN51 (Mandarino; Gomes, 2009).

O cultivo do cacau demanda equipamentos para implantação e manutenção do SAF, colheitas dos frutos, fermentação e secagem, uma vez que o produto é comercializado através de amêndoas secas. Assim, a modelagem econômica referente aos custos do SAF cacau envolve três etapas: (i) implantação; (ii) manutenção; (iii) beneficiamento. A primeira etapa contempla os custos de equipamentos necessários: se o agricultor for implantar um único hectare, terá os custos totais da aquisição dos equipamentos ( $\mathrm{R} \$ 7.310,00$ ), mas se ele pretende implantar mais de um hectare, o custo unitário dos equipamentos será proporcional, com limite inferior de $\mathrm{R} \$ 538,54$ em razão do processo de rateio baseado no princípio da depreciação ou vida útil desses equipamentos (Tabela 5). 
Tabela 5. Custos fixos para implantar 1 hectare do SAF Cacau.

\begin{tabular}{|c|c|c|c|c|c|c|c|}
\hline \multirow[b]{2}{*}{ Custos } & \multirow[b]{2}{*}{ Unidade } & \multirow[b]{2}{*}{ Qtde } & \multirow[b]{2}{*}{ Total $(\mathrm{R} \$)$} & \multicolumn{4}{|c|}{ Rateio baseado na depreciação } \\
\hline & & & & $\begin{array}{l}\text { Vida útil } \\
\text { (horas) }\end{array}$ & $\begin{array}{l}\text { Custo hora } \\
\text { (R\$) }\end{array}$ & Qtde horas 1 ha & $\begin{array}{l}\text { Custo }(\mathrm{R} \$) \\
/ / 1 \text { ha }\end{array}$ \\
\hline Perfurador/solo & um & 1 & $1.000,00$ & 11.520 & 0,09 & 65 & $\overline{5,64}$ \\
\hline KIT irrigação & um & 1 & $4.000,00$ & 9.216 & 0,43 & 900 & 390,63 \\
\hline Motosserra & um & 1 & 800,00 & 11.520 & 0,07 & 100 & 6,94 \\
\hline Kit EPI & $\mathrm{dv}$ & 1 & 300,00 & 2.304 & 0,13 & 900 & 117,19 \\
\hline Roçadeira & um & 1 & 900,00 & 11.520 & 0,08 & 100 & 7,81 \\
\hline Enxada & um & 1 & 80,00 & 2.304 & 0,03 & 100 & 3,47 \\
\hline Cavadeira & um & 1 & 90,00 & 2.304 & 0,04 & 20 & 0,78 \\
\hline Foice & um & 1 & 80,00 & 2.304 & 0,03 & 100 & 3,47 \\
\hline Facão & um & 1 & 60,00 & 2.304 & 0,03 & 100 & 2,60 \\
\hline Custo Fixo Total & & & $7.310,00$ & & sto Fixo Ra & eado & 538,53 \\
\hline
\end{tabular}

Fonte: Elaboração própria a partir de Andrade et al. (2020).

Ao considerar a hipótese desse modelo ser implantado em uma área aberta, pasto por exemplo, para amenizar os possíveis riscos causados por invasão de animais e destruição do plantio, foi inserido nas análises de custos o valor com cercamento da área. Ao utilizar um espaçamento entre as estacas de 3 metros, entre mourões de 50 metros e 5 fios de arame farpado, tem-se, para 400 metros lineares de cerca, suficientes para cercamento de 1 hectare, um custo total de R\$ $4.380,00$ (Andrade et al. 2020), incluindo a mão de obra necessária (R\$1.500,00).

Os custos variáveis para implantação do SAF Cacau totalizam R \$ 8.259,40 (Tabela 6). Sobre as quantidades das mudas de cacau, de banana e de espécie nativa foi adicionado um percentual de $20 \%$ a título de replantio. A adubação seguiu as orientações do principal órgão responsável pela atividade do cacau, a CEPLAC ${ }^{3}$.

O custo total da implantação do SAF cacau, primeira etapa, pode apresentar dois montantes. Se considerar a implantação de um único hectare, consequentemente, o custo fixo dos equipamentos será de $\mathrm{R} \$ 7.310,00$, que adicionado ao valor da cerca $(\mathrm{R} \$ 4.380,00)$ e ao total do custo variável $(\mathrm{R} \$ 8.259,40)$, tem-se um valor total de $\mathrm{R} \$ 19.949,40$. Se os equipamentos forem utilizados em mais de um hectare, ou seja, contabilizar apenas o tempo de sua utilização (R \$ 538,53), o custo total da implantação de 1 hectare de SAF Cacau cai para $\mathrm{R} \$ 13.177,93$.

${ }^{3}$ Comissão Executiva de Planejamento da Lavoura Cacaueira - informação disponível em: http://www.ceplac.gov.br/radar/cacau.htm 
Tabela 6. Custo variável para implantar 1 hectare do SAF Cacau.

\begin{tabular}{lccrrr}
\hline \multicolumn{1}{c}{ Custos } & $\begin{array}{c}\text { Unidades de } \\
\text { medida }\end{array}$ & Quantidades & $\begin{array}{c}\text { Custo } \\
\text { Unitário (R\$) }\end{array}$ & Total (R\$) & $\%$ \\
\hline Mudas de cacau & um & 998 & 1,50 & $1.497,60$ & 18,13 \\
Mudas de banana & um & 500 & 2,00 & $1.000,80$ & 12,12 \\
Mudas de nativas & um & 62 & 5,00 & 312,00 & 3,78 \\
Sementes de mucuna preta & $\mathrm{kg}$ & 3 & 7,00 & 21,00 & 0,25 \\
Sementes feijão de porco & $\mathrm{kg}$ & 2 & 7,50 & 15,00 & 0,18 \\
Calcário dolomítico & $\mathrm{kg}$ & 60 & 3,00 & 180,00 & 2,18 \\
Esterco bovino (2kg/cova) & $\mathrm{t}$ & 2 & 800,00 & $1.600,00$ & 19,37 \\
Adubo superfosfato simples & $\mathrm{kg}$ & 30 & 3,00 & 90,00 & 1,09 \\
Mão de obra - roçagem & $\mathrm{h}$ & 40 & 8,00 & 320,00 & 3,87 \\
Mão de obra - berços & $\mathrm{h}$ & 80 & 8,00 & 640,00 & 7,75 \\
Mão de obra - adubação & $\mathrm{h}$ & 24 & 8,00 & 192,00 & 2,32 \\
Mão de obra - plantio & $\mathrm{h}$ & 18 & 8,00 & 144,00 & 1,74 \\
Análise de solo & $\mathrm{hm}$ & 10 & 50,00 & 500,00 & 6,05 \\
Transporte & $\mathrm{um}$ & 1 & 500,00 & 500,00 & 6,05 \\
Assistência Técnica do projeto & $\mathrm{um}$ & 1 & $1.247,00$ & $1.247,00$ & 15,10 \\
\hline Custo Variável Total para Implantação & & & & $\mathbf{8 . 2 5 9 , 4 0}$ & $\mathbf{1 0 0}$ \\
\hline
\end{tabular}

Fonte: Elaboração própria a partir de Andrade et al. (2020).

Os custos na segunda etapa, manutenção do SAF, consistem em insumos, mão de obra e alguns equipamentos, totalizando $\mathrm{R}$ \$ 2.552,00 por ano (Tabela 7). A limpeza, a qual inclui aceiro para amenizar impactos de incêndios no SAF e controle de pragas, deverá ser realizada duas vezes ao ano.

Tabela 7. Custos anuais para manter o SAF Cacau.

\begin{tabular}{lccrrr}
\hline \multicolumn{1}{c}{ Custos } & $\begin{array}{c}\text { Unidade de } \\
\text { medida }\end{array}$ & Qtde. & $\begin{array}{c}\text { Custo } \\
\text { Unit (R\$) }\end{array}$ & Total (R\$) & $\%$ \\
\hline Calcário dolomítico & $\mathrm{kg}$ & 60 & 3,00 & 180,00 & 7,1 \\
Fertilizantes base NPK & $\mathrm{kg}$ & 150 & 5,00 & 750,00 & 29,4 \\
Adubação foliar & $\mathrm{kg}$ & 30 & 3,00 & 90,00 & 3,5 \\
Mão de obra - manejo de pragas & $\mathrm{h}$ & 100 & 8,00 & 800,00 & 31,3 \\
Mão de obra - roçagem/aceiro & $\mathrm{h}$ & 40 & 8,00 & 320,00 & 12,5 \\
Mão de obra - adubação & $\mathrm{h}$ & 24 & 8,00 & 192,00 & 7,5 \\
Foice & $\mathrm{um}$ & 1 & 80,00 & 80,00 & 3,1 \\
Facão & $\mathrm{um}$ & 1 & 60,00 & 60,00 & 2,4 \\
Enxada & $\mathrm{um}$ & 1 & 80,00 & 80,00 & 3,1 \\
\hline Custo Anual Total & & & & $\mathbf{2 . 5 5 2 , 0 0}$ & $\mathbf{1 0 0}$ \\
\hline
\end{tabular}

Fonte: Elaboração própria a partir de Andrade et al. (2020).

A terceira etapa, beneficiamento, corresponde aos custos fixos para colheita, transporte, fermentação, secagem e pesagem, tendo investimento inicial de $\mathrm{R} \$ 14.460,00$ e custo anual de $\mathrm{R} \$ 146,35$ (Tabela 8). Essa estimativa, para 1 hectare com

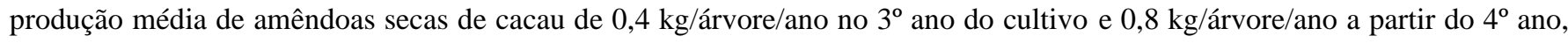
baseia-se na utilização do clone PS1319 (MANDARINO; GOMES, 2009). Ao considerar 832 pés de cacau, tem-se uma produção de $332,80 \mathrm{~kg}$ (ou 22,19 arrobas) no terceiro ano, passando para 665,60 kg/ano (44,37 arrobas) a partir do quarto ano. 
Tabela 8. Equipamentos necessários para colheita e beneficiamento de cacau de 1 hectare.

\begin{tabular}{|c|c|c|c|c|c|c|c|c|}
\hline \multirow[b]{2}{*}{ Custos } & \multirow{2}{*}{$\begin{array}{l}\text { Unidade } \\
\text { de medida }\end{array}$} & \multirow[b]{2}{*}{ Qtde } & \multirow{2}{*}{$\begin{array}{c}\text { Custo } \\
\text { Unitário (R\$) }\end{array}$} & \multirow[b]{2}{*}{ Total $(\mathrm{R} \$)$} & \multicolumn{4}{|c|}{ Rateio baseado na depreciação } \\
\hline & & & & & $\begin{array}{c}\begin{array}{l}\text { Vida útil } \\
\text { (horas) }\end{array} \\
\end{array}$ & $\begin{array}{c}\text { Custo hora } \\
(\mathrm{R} \$)\end{array}$ & $\begin{array}{c}\text { Qtde horas } \\
1 \text { ha }\end{array}$ & $\begin{array}{l}\text { Custo }(\mathrm{R} \$) \\
/ 1 \text { ha /ano } \\
\end{array}$ \\
\hline Kit EPI & $\mathrm{dv}$ & 1 & 300,00 & 300,00 & 2.304 & 0,13 & 200 & 26,04 \\
\hline Podão & un & 2 & 100,00 & 200,00 & 2.304 & 0,09 & 30 & 2,60 \\
\hline Facão & un & 1 & 60,00 & 60,00 & 2.304 & 0,03 & 100 & 2,60 \\
\hline Caixas cacau & un & 2 & 250,00 & 500,00 & 2.304 & 0,22 & 30 & 6,51 \\
\hline Cochos/fermentação & um & 3 & 800,00 & $2.400,00$ & 11.520 & 0,21 & 60 & 12,50 \\
\hline Estufa/secagem & um & 1 & $5.000,00$ & $5.000,00$ & 11.520 & 0,43 & 100 & 43,40 \\
\hline Balança/pesagem & un & 1 & $1.400,00$ & $1.400,00$ & 11.520 & 0,12 & 5 & 0,61 \\
\hline Animal & um & 2 & $1.000,00$ & $2.000,00$ & 23.040 & 0,09 & 100 & 8,68 \\
\hline Cangalha & um & 2 & 500,00 & $1.000,00$ & 11.520 & 0,09 & 100 & 8,68 \\
\hline Panacum cipó & um & 4 & 400,00 & $1.600,00$ & 4.608 & 0,35 & 100 & 34,72 \\
\hline Investimento inicial & & & & $14.460,00$ & & to Fixo ar & uual & 146,35 \\
\hline
\end{tabular}

Fonte: Elaboração própria a partir de Andrade et al. (2020).

Além do cacau, o presente SAF tem outras fontes de receita e, consequentemente, custos para colheita e armazenamento. A banana tem uma função de sombreamento das mudas de cacaueiros e gera frutos que podem ser comercializados. A outra espécie com finalidade econômica é a sapucaia, a qual é nativa do bioma Mata Atlântica, presente do Ceará até o Rio de Janeiro, sendo encontrada com maior abundância no Sul da Bahia e no Espírito Santo. Trata-se de uma espécie interessante, como não madeireira, pela produção de castanhas comestíveis, de alto valor nutritivo e medicinal (Rolim; Piotto, 2018). Esses três produtos têm início de produção de frutos em períodos diferentes. Conforme dados coletados na pesquisa de campo, os custos de colheita e beneficiamento ocorrerão da seguinte forma: colheita da banana no segundo e terceiro anos, com valor anual de R\$2.000,00; a do cacau inicia no terceiro ano demandando cerca de $\mathrm{R} \$ 3.600,00$ por ano; já a sapucaia, inicia sua produção a partir do oitavo ano e demanda cerca de $\mathrm{R} \$ 1.760,00$ por ano (Tabela 9).

Tabela 9. Custos estimados para colheita e beneficiamento dos frutos do SAF Cacau.

\begin{tabular}{|c|c|c|c|c|c|}
\hline Custos & $\begin{array}{l}\text { Unidade de } \\
\text { medida }\end{array}$ & Qtde. & $\begin{array}{l}\text { Custo Unitário } \\
\text { (R\$) }\end{array}$ & Total $(\mathrm{R} \$)$ & Anos \\
\hline Mão de obra - colheita banana & $\mathrm{h}$ & 200 & 8,00 & $1.600,00$ & \multirow{2}{*}{$2^{o}$ e $3^{o}$} \\
\hline Mão de obra - transporte & $\mathrm{h}$ & 50 & 8,00 & 400,00 & \\
\hline Custo com colheita da banana & & & & $2.000,00$ & \multirow{4}{*}{$\begin{array}{c}\text { A partir do } \\
3^{\circ}\end{array}$} \\
\hline Mão de obra - colheita cacau & $\mathrm{h}$ & 200 & 8,00 & $1.600,00$ & \\
\hline Mão de obra - transporte & $\mathrm{h}$ & 50 & 8,00 & 400,00 & \\
\hline Mão de obra - fermentação/secagem & $\mathrm{h}$ & 200 & 8,00 & $1.600,00$ & \\
\hline \multicolumn{3}{|c|}{ Cus to com colheita e be ne ficiamento do cacau } & & $3.600,00$ & \\
\hline Mão de obra - colheita da sapucaia & $\mathrm{h}$ & 200 & 8,00 & $1.600,00$ & A partir do \\
\hline Mão de obra - transporte & $\mathrm{h}$ & 20 & 8,00 & 160,00 & $8^{\circ}$ \\
\hline Cus to com colheita da sapucaia & & & & $\mathbf{1 . 7 6 0 , 0 0}$ & \\
\hline
\end{tabular}

Fonte: Elaboração própria a partir de Andrade et al. (2020).

Para calcular o fluxo de caixa do presente SAF, foram consideradas, as seguintes premissas: (i) cacau com produção de $332,80 \mathrm{~kg}$ (ou 22,19 arrobas) no terceiro ano, passando para 665,60 kg/ano (44,37 arrobas) a partir do quarto ano; (ii) preço da arroba de cacau $(15 \mathrm{~kg}$ ) a $\mathrm{R} \$ 200,00$; (iii) duas colheitas da bananeira: na primeira, produção de banana de $10 \mathrm{~kg} / \mathrm{planta}$ a partir de 1,5 ano, reduzindo para $8 \mathrm{~kg} /$ planta no segundo corte (perfilhos); (iv) preço do kg da banana de R $\$ 3,00$; (v) produção de cada 
árvore de sapucaia: $8 \mathrm{~kg}$ a partir do $8^{\circ}$ ano; $10 \mathrm{~kg}$ a partir do $12^{\circ}$ ano; (vi) preço do $\mathrm{kg}$ de sapucaia pago ao produtor $\mathrm{R} \$ 30,00$. Consequentemente, num horizonte de 20 anos, esse SAF apresenta-se economicamente viável, com VPL de R \$44.608,68, TIR de $17 \%$ e Payback Simples de 7,7 anos (Tabela $10^{4}$ ).

Tabela 10. Indicadores econômicos e financeiros do SAF Cacau.

\begin{tabular}{l|rrrrr|r}
\hline \multirow{2}{*}{ Custos e Receitas estimadas } & \multicolumn{4}{c|}{ Anos } & \multirow{2}{*}{ TOTAL } \\
\cline { 2 - 5 } & \multicolumn{1}{c}{0} & De 1 a 5 & De 6 a 10 & De 11 a 15 & De 16 a 20 & \\
\hline Equipamentos - Implantação & $13.177,93$ & 0,00 & 0,00 & 0,00 & 0,00 & $13.177,93$ \\
Custo de Manutenção & & $12.760,00$ & $12.760,00$ & $12.760,00$ & $12.760,00$ & $51.040,00$ \\
Equipamentos - beneficiamento & $14.460,00$ & 731,77 & 731,77 & 731,77 & 731,77 & $17.387,08$ \\
Colheita da Banana & & $4.000,00$ & 0,00 & 0,00 & 0,00 & $4.000,00$ \\
Colheita do Cacau & & $10.800,00$ & $18.000,00$ & $18.000,00$ & $18.000,00$ & $64.800,00$ \\
Colheita da Sapucaia & & 0,00 & $5.280,00$ & $8.800,00$ & $8.800,00$ & $22.880,00$ \\
\hline TOTAL DOS CUSTOS & $27.637,93^{\prime \prime}$ & $28.291,77^{\circ}$ & $36.771,77^{\circ}$ & $40.291,77^{\circ}$ & $40.291,77$ & $173.285,01$ \\
\hline Receita da Banana & & $22.518,00$ & 0,00 & 0,00 & 0,00 & $22.518,00$ \\
Receita do Cacau & & $22.186,00$ & $44.370,00$ & $44.370,00$ & $44.370,00$ & $155.296,00$ \\
Receita da Sapucaia & & 0,00 & $23.760,00$ & $47.520,00$ & $49.500,00$ & $120.780,00$ \\
\hline TOTAL DAS RECEITAS & 0 & $44.704,00$ & $68.130,00$ & $91.890,00$ & $93.870,00$ & $298.594,00$ \\
\hline SALDO & $-27.637,93$ & $16.412,23$ & $31.358,23$ & $51.598,23$ & $53.578,23$ & $125.308,99$ \\
\hline SALDO ACUMULADO & $-27.637,93$ & $-11.225,70$ & $20.132,53$ & $71.730,76$ & $125.308,99$ \\
\hline Indicadores & VPL & $44.608,68$ & \multicolumn{5}{c}{ Tayback } & 7,7 anos \\
\hline
\end{tabular}

Fonte: Elaboração própria a partir de Andrade et al. (2020).

O SAF cacau, além de apresentar viabilidade econômica a partir da comercialização dos seus frutos, apresenta outro benefício ambiental para a Mata Atlântica: estocagem de carbono. O cultivo de cacau representa quase metade da cobertura florestal existente no sul da Bahia (48\%), entretanto, contribui com a maior parte (59\%) do carbono estocado na região (Schroth et al. 2015). Os autores afirmam que a cabruca contribui com 59\% dos estoques totais de carbono na vegetação arbórea da região cacaueira da Bahia, enquanto os remanescentes de floresta natural são responsáveis por 32\% e pousios por 9\%, demonstrando a relevância do cacau no sequestro de carbono.

\section{Considerações Finais}

O SAF Cacau poderia gerar consideráveis inputs na economia e na conservação ambiental do MAPES. Considerando, hipoteticamente, a recuperação dos 3.165 ha de passivo ambiental das pequenas propriedades utilizando o SAF Cacau, e como cada hectare tem uma quantidade de 52 indivíduos de espécies nativas, esse arranjo produtivo geraria um incremento de 164.580 novas árvores nativas na região. Consequentemente, ao valor médio de $\mathrm{R} \$ 5,00$ cada muda nativa, tem-se um incremento monetário nos viveiros locais de cerca de $\mathrm{R} \$ 822.900,00$.

Cada hectare de SAF Cacau demanda, ao longo de 20 anos, cerca de $\mathrm{R} \$ 97.035,00$ com mão de obra: $\mathrm{R} \$ 1.500,00$ com cerca; R \$ 2.543,00 com implantação; R \$ 1.312,00 com manutenção; e, R\$ 91.680,00 com colheita e beneficiamento. Logo, a restauração dos 3.165 mil ha geraria uma demanda por mão de obra cujo volume monetário seria de $\mathrm{R} \$ 307$ milhões ao longo dos 20 anos. Dividindo esse valor por $\mathrm{R} \$ 1.650,00$ mensais (salário mínimo + 50\% de encargos sociais) e por 240 meses (20 anos), tem-se uma quantidade de 775,5 profissionais trabalhando na cadeia produtiva da restauração no MAPES. Considerando

\footnotetext{
${ }^{4}$ Embora o fluxo de caixa esteja apresentado em 4 períodos de 5 anos cada, como forma de compactação da tabela, os cálculos foram realizados anualmente.
} 
também para esse período o faturamento bruto de $\mathrm{R} \$ 298.594,00 /$ ha, a recuperação do passivo ambiental incrementaria uma receita bruta de $\mathrm{R} \$ 945$ milhões na região.

Denota-se o incremento positivo do SAF Cacau, tanto a nível ambiental quanto econômico. Ademais, esse SAF tem a possibilidade ainda de acessar programas que visam Pagamento por Serviços Ambientais (PSA). Outra possibilidade é a comercialização de créditos de carbono, uma vez que o SAF Cacau absorve considerável quantidade de carbono.

Para as instituições de crédito, o presente SAF apresenta viabilidade econômica. Entretanto, a viabilidade financeira, recursos para investimentos até o momento das entradas das receitas oriundas da produção do SAF cacau, caberá as instituições de crédito. Salienta-se que uma das características relevantes do cacau, do ponto de vista de negócios, é que o mesmo possui altíssima liquidez, ou seja, em praticamente todos os municípios da região existem pontos de compra do produto. Ademais, as indústrias moageiras de cacau localizadas no sul da Bahia têm uma demanda anual de cerca de 300 mil toneladas, enquanto a produção baiana gira em torno de 160 mil toneladas/ano, demonstrando claramente que tudo que for produzido (3.165 ha x $44 @$ =139.260@/ano) poderá ser consumido.

\section{Agradecimentos}

O presente artigo é um recorte da pesquisa denominada Análise econômica da cadeia produtiva da recuperação da vegetação nativa na região do Mosaico de Áreas Protegidas do Extremo Sul da Bahia (MAPES) financiada pelo Ministério do Meio Ambiente (Departamento de Conservação de Ecossistemas - Secretaria de Biodiversidade) através do FUNBIO - Fundo Brasileiro para a Biodiversidade (Andrade et al., 2020). Na sua execução contou com a participação das seguintes instituições: Econamfi Projetos e Pesquisas; Escritório de Projetos (EPEC) da Universidade Estadual de Santas Cruz (UESC); e as Organizações Não-Governamentais Natureza Bela e Instituto Ciclos de Sustentabilidade de Cidadania.

\section{Referências}

Andrade, D. C. \& Fasiaben, M. C. R. (2009). A utilização dos instrumentos de política ambiental para a preservação do meio ambiente: o caso dos Pagamentos por Serviços Ecossistêmicos (PSE). Revista REE [Uberlândia, MG], 24, (1).

Andrade, J. C. P. et al. (2015). A economia do cacau no Sul da Bahia. In: Gomes, A. S., \& Pires, M. M. (Org.). Cacauicultura: estrutura produtiva, mercados e perspectivas. Ilhéus: Editus, 272 p.

Andrade, J. C. P. (Coord.) et al. (2020). Análise econômica da cadeia produtiva da recuperação da vegetação nativa na região do Mosaico de Áreas Protegidas do Extremo Sul da Bahia (MAPES). Brasília: Ministério do Meio Ambiente. http://cooperacaobrasil-alemanha.com/Mata_Atlantica/Analise-CadeiaEconomica_MAPES.pdf

Barbosa, F.A. et al. (2010). Produtividade e eficiência econômica de sistemas de produção de cria, recria e engorda de bovinos de corte na região sul do estado da Bahia. Arquivo Brasileiro Medicina de Veterinária e Zootecnia, 62, 677-685.

Bahia. (2014). Casa Civil. Decreto No 15.180 DE 02/06/2014 - Regulamenta a gestão das florestas e das demais formas de vegetação do Estado da Bahia, a conservação da vegetação nativa, o Cadastro Estadual Florestal de Imóveis Rurais - CEFIR, e dispõe acerca do Programa de Regularização Ambiental dos Imóveis Rurais do Estado da Bahia e dá outras providências. Diário Oficial do Estado da Bahia, 3 jun 2014.

Bahia. (2019). Sistema de Informações Municipais. Superintendência de Estudos Econômicos e Sociais da Bahia. Salvador, 2019. http://sim.sei.ba.gov.br/sim/index.wsp

Brasil. (2013). Sistema Nacional de Cadastro Rural. INCRA. Brasília, DF, 2013. http://www.incra.gov.br/sites/default/files/uploads/estruturafundiaria/regularizacao-fundiaria/indices-cadastrais/indices_basicos_2013_por_municipio.pdf

Brasil. (2010). Ministério do Meio Ambiente. Portaria No 492, de 17 de dezembro de 2010. Brasília, DF, 2010. http://www.mma.gov.br/legislacao/areasprotegidas.html?download=825:portaria-n-492-de-17-de-dezembro-de-2010

Brasil. (2000). Presidência da República. Lei 9.985, de 18 de julho de 2000. Regulamenta o art. 225, § 1o, incisos I, II, III e VII da Constituição Federal, institui o Sistema Nacional de Unidades de Conservação da Natureza e dá outras providências. Brasília, DF, Diário Oficial da União, p. 1, 18/07/2000.

Brasil. (2012). Presidência da República. Lei 12.651 de 25/3/2012. Dispõe sobre a proteção da vegetação nativa; altera as Leis nos 6.938 , de 31 de agosto de 1981, 9.393, de 19 de dezembro de 1996, e 11.428, de 22 de dezembro de 2006; revoga as Leis $n^{\text {os }} 4.771$, de 15 de setembro de 1965 , e 7.754 , de 14 de abril de 1989, e a Medida Provisória nº 2.166-67, de 24 de agosto de 2001; e dá outras providências. Brasília, DF, Diário Oficial da União, p. 1, $28 / 5 / 2012$.

Brasil. (2019). Serviço Florestal Brasileiro. SICAR. Brasília, DF. http://www.car.gov.br/publico/imoveis/index. 
Research, Society and Development, v. 10, n. 4, e25110413820, 2021

(CC BY 4.0) | ISSN 2525-3409 | DOI: http://dx.doi.org/10.33448/rsd-v10i4.13820

Brito, D. M. C. et al. (2011). Conflitos socioambientais no século XXI. PRACS: Revista de Humanidades do Curso de Ciências Sociais da UNIFAP, 4, 51-58.

Carvalho Júnior, J. N. (2011). Diagnóstico da pecuária leiteira na microrregião de Itapetinga-Bahia. Itapetinga-BA: UESB, 119 fl.

Castro, A. M. G., Lima, S.M. V. \& Cristo, C. M. P. N. (2002). Cadeia produtiva: marco conceitual para apoiar a prospecção tecnológica. In: XXII Simpósio de Gestão da Inovação Tecnológica. http://fcf.unse.edu.ar/archivos/posgrado/2002.cadeiaprodutiva.marcoconceitual.prospeccaotecnologica.pdf.

Cerqueira Neto, S. P. G. (2012). Três décadas de eucalipto no Extremo Sul da Bahia. GEOUSP - Espaço e Tempo, 31, 55 - 68.

Constanza, R. et al. (1998) The value of the world's ecosystem services and natural capital. Ecological Economics, Solomons, 25(1):3-15.

Dortzbach, D. et al. (2021). Impacto do código florestal e da lei da Mata Atlântica em áreas de mata ciliar de propriedades rurais do Estado de Santa Catarina. Research, Society and Development, 10(2), 1-14.

Ferreira, C. L. R., Pereira, K. A. \& Logarezzi, A. J. M. (2019). Territorialização no Extremo Sul na Bahia e Conflitos Socioambientais: disputando modelos de educação e desenvolvimento. Geosul, 34(71), 739-764

Lima, R. M. \& Shiraishi Neto, J. (2015). Conflitos socioambientais: o direito ambiental como legitimador da atuação do estado no Jardim Icaraí, Curitiba. Ambiente \& Sociedade, 18(2), 133-148.

Little, P. E. (2006). Ecologia política como etnografia: um guia teórico e metodológico. Horizontes Antropológicos, 12(25), 85-103.

Lobão, D. E. \& Valeri, S. V. (2009). Sistema cacau-cabruca: conservação de espécies arbóreas da floresta atlântica. Agrotrópica, 21(1), 43-54.

Mandarino, E. P. \& Gomes, A. R. S. (2009). Produtividade do cacaueiro (Theobroma cacau L.) cultivados em blocos monoclonais, no sul da Bahia, Brasil. Ilhéus, CEPLAC/CEPEC. Boletim Técnico. 197, 32p.

MAPBIOMAS. Estatísticas. MapBiomas, 2019. https://mapbiomas.org/estatisticas.

Muñoz-Sáez, A, Perez-Quezada J. F. \& Estades, C. F. (2017). Agricultural landscapes as habitat for birds in central Chile 2017. Rev Chil Hist Nat, 90:3.

Pardini, R. (2004). Effects of forest fragmentation on small mammals in an Atlantic Forest landscape. Biodiversity and Conservation, 13: 2567-2586.

Rocha, L. B. (2008). A região cacaueira da Bahia - dos coronéis à vassoura de bruxa: saga, percepção, representação. Ilhéus: Editus.

Rolim, S. G. \& Piotto, D. (Editores). (2018). Silvicultura e tecnologia de espécies da Mata Atlântica. Belo Horizonte, Editora Rona, 160 p.

Schroth, G., Bede, L.C. \& Paiva, A. O. et al (2015). Contribution of agroforests to landscape carbon storage. Mitig Adapt Strateg Glob Change, 20, 1175-1190.

Shackelford G. E. et al. (2015). Conservation planning in agricultural landscapes: Hotspots of conflict between agriculture and nature. Diversity and Distributions, 21, 357-367.

Siqueira, R. P. et al. (2021). Viabilidade econômica da produção da tilápia do Nilo como atividade secundária em propriedades rurais no Estado do Rio de Janeiro. Research, Society and Development, 10(2), 1-17.

Virgens Filho, A. C. (2017). Sistemas Agroflorestais (SAFs) com a Seringueira. V Encontro Técnico Nacional de Heveicultura Barretos, São Paulo, 24 de novembro.https://www.defesa.agricultura.sp.gov.br/www/gdsv/conteudoPalestras/V-Encontro-2017/09-sistemasagroflorestaiscomaseringueira-

AdoniasdeCastroVirgensFilho.pdf . 